\title{
Valuing the Relationship Between Drug and Alcohol Use and Life Satisfaction: Findings from the Crime Survey for England and Wales
}

\author{
Anna Maccagnan ${ }^{1}$ (D) $\cdot$ Tim Taylor $^{1} \cdot$ Mathew P. White ${ }^{1}$
}

Published online: 5 April 2019

(C) The Author(s) 2019

\begin{abstract}
We analysed the relationship between drug use and wellbeing using data from the Crime Survey for England and Wales. We focused on cannabis use, the most commonly used drug, but also controlled for use of other drugs, alcohol consumption and a range of potential confounds. Measuring life satisfaction on a 0-10 scale, linear models found that people who had never used cannabis had significantly higher scores than current users (0.54). Never having used other types of drugs was also associated with 0.37 extra life satisfaction points. Moderate alcohol use (1-2 days per week) was associated with higher life satisfaction than abstainers or more regular drinkers. Following the "life satisfaction approach", we estimated the extra income that would be needed to compensate for the wellbeing loss associated with cannabis use. Accounting for income endogeneity, our results suggested that being a current cannabis user may cost an individual over $£ 5600$ per year, in terms of lost wellbeing, while being a current user of other drugs may cost approximately $£ 4000$ per year. While acknowledging possible reverse causality, we estimated the annual population cost of drug use may be as high as $£ 10.7 \mathrm{bn}$ in terms of lost wellbeing.
\end{abstract}

Keywords Drug use · Cannabis · Life satisfaction · Wellbeing · Compensation value · CSEW

\section{Introduction}

Although illicit drug use appears to be slowly declining in England and Wales, the best available evidence still suggests that as many as 1 in 12 (8.4\%) of adults aged 16-59 years, or 2.7 million people, took illegal drugs in 2015/2016 (Office for National Statistics (ONS) 2016a). Drug use is the subject of much debate, with a significant body of research focused on the potential negative effects drug use might have on user's psychological health and wellbeing (e.g. Brook et al. 2002; Levy 2008; Allen and Holder 2014). Some have suggested that access to certain drugs may positively affect wellbeing: Anderson et al. (2014)

Anna Maccagnan

a.maccagnan@exeter.ac.uk

1 European Centre for Environment and Human Health, College of Medicine and Health, University of Exeter, Knowledge Spa, Royal Cornwall Hospital, Truro TR1 3HD, UK 
found for example lower suicide rates in the US states where cannabis has been legalised for therapeutic purposes. It is in this context that we examined the association between wellbeing, in terms of an individual's overall satisfaction with life, and drug use, using special license data drawn from the Crime Survey for England and Wales (CSEW). Given that the CSEW also provides information on household income, we also attempted to value the economic cost of taking drugs on wellbeing using the "life satisfaction approach", an approach increasingly used in the literature to assign a monetary value to non-market goods (e.g. Her Majesty's Treasury (HMT) 2011; Oswald and Powdthavee 2008; Tsurumi and Managi 2016). Of course, establishing causality on this issue is difficult (Moore et al. 2007) as drugs may not just influence life satisfaction-either directly through their consumption or via the detrimental health and social consequences of consuming drugs (Allen and Holder 2014)_but drug taking may also be a coping strategy to deal with low wellbeing levels (Miller and Plant 2002). Although our cross-sectional data cannot directly answer issues of causality we were still able to explore whether an association between drug use and wellbeing exists controlling for a range of potential confounders such as health, employment and marital status, and attempt to quantify any relationship in monetary terms. This allowed us to compute the overall cost of taking drugs at the national level, and to compare it in magnitude to the cost of other well-recognised social problems, such as smoking and air pollution.

The current research focused on the use of cannabis and other drugs (combined). Cannabis was explored separately as it was by far the most widely used drug in the CSEW dataset. The remaining drugs were combined, despite potentially having different relationships with wellbeing, because our sample included too few individuals in each specific drug category, rendering analysis and interpretation at this level of specificity unreliable. This is consistent with earlier findings. For instance, previous work has reported the next most popular drugs after cannabis (6.6\% of the adult population) are powder cocaine and ecstasy, with annual levels of use of just $2.4 \%$ and $1.6 \%$ respectively (ONS 2014a). We also distinguished between three groups of individuals ${ }^{1}$ : those who report never having used the drug (never users); those who have used the drug in their life but not in the last 12 months (past users); and those who have used the drug in the last 12 months (current users). We were unable to explore use frequency in more depth as this information is not provided in the dataset. Nevertheless, inferences about use frequency can be made based on the 2014a ONS data, which suggests that $43 \%$ of current cannabis users use it more than once a month, while users of other types of drug do so less frequently (e.g. only $13 \%$ of powder cocaine users, $12 \%$ of amphetamine users and $4 \%$ of ecstasy user use the drug more than once a month). Finally, given the much wider use of alcohol, we also compared the relationship with alcohol use and wellbeing with drug use and wellbeing to contextualise our findings.

The paper is organised as follows. Section 2 reviews the literature on the association between drug use and wellbeing. Section 3 presents the data and descriptive statistics. Section 4 presents the empirical strategy, including the regression model and the computation of the cost of drugs using the life satisfaction approach. Results are presented in Sect. 5 and discussed in Sect. 6, where the overall wellbeing benefit that could potentially be enjoyed by giving up drugs at the national level is also computed. Section 7 summarises the findings and the last Section concludes.

1 This distinction is made also by MacDonald and Pudney (2000). 


\section{Literature Review}

\subsection{Drugs and Wellbeing}

Substance misuse is an important social issue, associated with a range of mental health problems (Moore et al. 2007) and antisocial behaviour and crime (Bennet and Holloway 2005; Bennet et al. 2008), in part to fund drug use itself (Bennet et al. 2008; Cross et al. 2001; Kopak et al. 2014).

\subsubsection{Impact of Drugs on Wellbeing}

A considerable body of research has suggested that use of drugs may lead to lower wellbeing and particularly to the development of depressive symptoms in later life following early consumption (e.g. Brook et al. 2002), but it is unclear whether this relationship is due to the drug itself or due to the circumstances surrounding its use. For instance Semple et al. (2005) argued that depressive symptoms associated with methamphetamine use are not merely due to negative life circumstances associated with drug use such as poorer employment, health and family, but can be directly attributed to the use of the drug itself. By contrast, using a sample of undergraduate students, Allen and Holder (2014), argued that it is the circumstances around the use of marijuana (e.g. poor attendance and academic performance), rather than the chemical substance itself, which is associated with poorer wellbeing. Although clearly an important issue for future study, this distinction is less relevant to the current research which focused mainly on an estimate of the costs of this loss on wellbeing rather than the complex causal pathways through which it might have operated. Moreover, some studies have found a positive relationship between drug use and wellbeing. It has been shown that marijuana legalization is associated with decreasing suicide rates, which may be partially the result of a decrease in alcohol consumption (Anderson et al. 2014).

\subsubsection{Other Factors Playing a Role in the Drug-Wellbeing Relationship}

Theoretical (Arnett 2005) and empirical contributions (Miller and Plant 2002) have pointed out the existence of other factors associated with substance use, suggesting for example that using drugs may be a strategy to cope with low levels of wellbeing. In a study on a sample of adolescent cannabis users, Miller and Plant distinguished between three different types of users. First, people using the drug for recreational purposes; second, those who used drugs within a wider context of anti-social delinquent behaviours; third, individuals that felt unsatisfied with how their life was going, using the drug for "self-medication". Levy (2008) also theorised that individuals from low socioeconomic groups consuming drugs for self-medication may end up trapped in a "vicious circle" due to the negative effect of drugs on employment and social outcomes.

These results lead to some reflections. The first is that it is not surprising that drug use is more widespread among younger people, especially in the case of recreational drugs taken when together with friends. ONS (2016a) data, for example, shows that in England and Wales $18 \%$ of people aged 16-24 years have used drugs at least once in the last year, against $8.4 \%$ in the broader category of 16-59 years. The early twenties represents an age in which the control from parents starts weakening - especially in the case of students living away from home (see Bennet and Holloway 2015 for a comparison between students 
and non-students), that have not yet experienced that "turning point" in life (i.e. starting employment or starting a family) associated with a greater degree of social control that discourages delinquent behaviour in general (Corman et al. 2011; Walker et al. 2013). Levitt (1998) also showed that coming of age is associated with a sharp decrease in crime rates in general, this being higher the severer the punishments for adults are compared to those for youths. Along these lines, Arnett (2005) theorized that so-called "emerging adults" using drugs consider this a "behaviour that is acceptable at their current age but one that they will give up in the course of growing into adulthood" (p. 247).

Second, personality plays an important role in drug use. Arnett (2005) hypothesised that optimistic individuals are more likely to use drugs, as they tend to underestimate the harmful effect drugs can have on their life. Along these lines, Peretti-Watel (2006) found that cannabis users have higher scores of risk denial compared to non-users. In the study by Allen and Holder (2014) marijuana users tended to score higher in "Openness to experience" and lower in "Agreeableness" and "Conscientiousness". This is consistent with the results by Tartaglia et al. (2017b). Allen and Holder (2014) also found that the negative social consequences of the drug are more severely felt by individuals high in "Neuroticism".

The third reflection is about the issue of reverse causality in the drug-wellbeing link. Among the papers reviewed by Moore et al. (2007), one of the most appropriate and commonly used methods to deal with the problem appears to be using panel data and controlling for the presence of mental health problems at some point earlier in time. In our research, given the cross-sectional nature of the dataset used, we were not able to fully address this issue. In order to reduce the bias associated with it, we controlled for a number of personal characteristics, such as health status, employment condition and marital status, which could at least in part explain the endogeneity issue. We are also aware that there may be a reciprocal association between wellbeing and income with happier people tending to earn more, even some years later (De Neve and Oswald 2012), and higher income (even through lottery wins) associated with greater well-being (possibly after a lag period, Gardner and Oswald 2007). We attempted to account for this using an instrumental variable approach proposed by Fujiwara et al. (2014, see Section 4.3).

\subsection{Alcohol Consumption and Wellbeing}

In this paper we also controlled for the link between wellbeing and alcohol consumption, a theme which has been already analysed by part of the literature. Gil-Lacruz and Gil-Lacruz (2010) found evidence of a significant effect of drinking on the prescription of tranquilizers among Spanish adolescents, holding also when taking into account reverse causality issues. Baumberg Geiger and MacKerron (2016) analysed data from the British Cohort Study and found that heavy drinking is a significant predictor of lower wellbeing. A similar result is also reported by Dietze et al. (2013) in an analysis on a sample of injection drug users that found a significant negative effect of drinking on wellbeing, even controlling for type and intensity of drug use. On the other hand, other studies have suggested that drinking may be a way to cope with stress and anxiety (Lanier et al. 2001; Tartaglia et al. 2017a). 


\subsection{The Welfare Cost of Drug Use}

The current research extends most previous work by going beyond exploring the association between drug use and wellbeing and attempting to also evaluate the cost of drug use using the "life satisfaction approach". This relatively novel approach (presented in more detail in Sect. 4) draws upon the analysis of the relationship between life satisfaction and income to compute the equivalent value of a range of non-market goods (HMT 2011), such as social relationships (Powdthavee 2008; Orlowski and Wicker 2015) and marriage (Qary 2014). In the same way, it is used to calculate the equivalent amount of money that would be needed to compensate for the existence of problems, such as housing problems (Fujiwara 2013) and negative life events, such as experiencing unemployment (Powdthavee 2008) or the death of a family member (Oswald and Powdthavee 2008).

To the best of our knowledge, only Powdthavee and van den Berg (2011) have used the life satisfaction approach in the context of drug use, focusing in particular on alcohol and drug problems, along with a number of other health issues. In their paper, they used BHPS panel data and distinguished between a level and a shock effect of income and health problems, reflecting respectively how the average value of these variables, as well as their annual shift from the average, affects life satisfaction. Their results suggested that, overall, "relief from alcohol and drug related problems" is worth approximately $£ 9$ million a year/per person. Clearly this amount seems very high and thus the approach was further elaborated by Fujiwara (2013). Specifically, Fujiwara used an instrumental variable approach to deal with the endogeneity problem in the incomewellbeing relationship. Using an unbiased coefficient for income and drawing upon the health problems coefficients estimated by Powdthavee and van den Berg (2011), Fujiwara concluded that overcoming alcohol and drug problems is worth $£ 24,000$ a year/ per person, a much lower, probably more realistic figure. The current research presents findings using both approaches for comparison (though of note unlike the BHPS there is no within-person variance over time in our cross-sectional data so we are not directly comparing like with like).

The life satisfaction approach measures the value of non-market goods and life events looking at how they impact subjective wellbeing, i.e. reflecting the point of view of the individual. A different perspective-looking mainly at the costs of drug use for the society-is instead the focus of another part of the literature (e.g. Lievens et al. 2017). Within this literature, the direct drugs-related health and crime expenditures imposed to the society are taken into account together with the indirect productivity losses and intangible quality of life losses. This approach was taken by the Drug Treatment Outcomes Research Study (DTORS). This study measured the benefits of treating drug problems using follow-up interviews on a sample of approximately 1800 individuals being treated in a structured setting in England (Davies et al. 2009; Donmall et al. 2009). DTORS took into account the benefits of the treatment in terms of health outcomes, as measured by Quality Adjusted Life Years (QALYs), and avoided costs for society from reduced criminal misconduct and lower access to public services to deal with health and social problems. Results suggested a total benefit per person of approximately $£ 6500$ a year, with a benefit-cost ratio of about $2.5: 1$. Given that this is a much broader impact assessment than that used by the life satisfaction approach it is interesting to see how much lower this figure is even compared to Fujiwara's (2013) $£ 24,000$ a year/per person. 


\subsection{Contribution to the Literature}

In sum, the current paper contributes to the existing literature by using data drawn from the Crime Survey for England and Wales to explore how reported use of drugs is related to life satisfaction and, following Powdthavee and van den Berg (2011) and Fujiwara (2013), attempted to value the individual cost associated to taking drugs, in terms of wellbeing loss. The current research distinguished between cannabis and other drugs and between current users, past users and never users. As far as we aware, this is novel and sheds light on the wellbeing costs of different types of drugs. Our analysis has been partly limited by the cross-sectional nature of the available data. In fact, we are not able to draw causal conclusions on the drug use-wellbeing relationship. Nevertheless, we have tried to address the reverse causality issue by including a number of socio-demographic covariates which are likely to play a role in this relationship, in order to partly mitigate the problem. Moreover, in dealing with the relationship between income and wellbeing, we have drawn upon the findings of previous studies, in an attempt to provide unbiased measures of the monetary cost of drug consumption. The computed figures were then used to extend our findings to compute the overall cost of taking drugs at the national level. Finally, along with the cost of drugs, the value of drinking alcohol was measured, as a function of drinking frequency.

\section{Data and Descriptive Statistics}

The data used in this analysis was the 2013-2014 Crime Survey for England and Wales (CSEW), a survey representative of the population living in private households in England and Wales. For each household in the sample, one adult is randomly selected to be interviewed (ONS 2015a). The CSEW mainly investigates whether the respondent has been a victim of criminal offences and his perceptions and attitudes towards crime. However, the questionnaire also includes self-completion modules collecting information about the consumption of drugs and alcohol, the engagement in anti-social behaviours, together with questions on subjective wellbeing (ONS and TNS 2014). The drugs and drinking modules are administered only to individuals aged 16 to 59, while the questions on wellbeing are asked only to a further subsample of observations (approximately 5200 individuals provide a valid answer to the question on life satisfaction). Once observations with missing information were excluded, our sample consisted of 4405 observations, made up of 2038 men and 2367 women aged 16 to 59-the age group to which self-completion modules are directed.

The variables used in the analysis were the following.

Life satisfaction Life satisfaction is measured through the question "Overall, how satisfied are you with your life nowadays?" Responses are reported on a 0-10 scale, where 0 indicates "Not at all" satisfied and 10 indicates "Completely" satisfied.

Drug use The data investigate the use of different types of drugs: amphetamines, methamphetamines, cannabis, cocaine, crack, ecstasy, heroin, acids, magic mushrooms, methadone, tranquillizers, poppers, anabolic steroids, ketamine, mephedrone and other unknown drugs. For each type of drug, the respondent is asked whether s/he has ever taken the drug in his life and whether s/he has taken the drug in the last 12 months. For the purpose of this analysis, we looked at cannabis and we collapsed all other drug categories into a single variable capturing any other drug. We then distinguished between three categories of individuals: those who have never used the drug; those who have used the drug in their life but 
not in the last 12 months (past users); those who have used the drug in the last 12 months (current users).

Alcohol use The CSEW collects a number of questions on alcohol consumption. In this analysis we looked at the consumption of alcoholic drinks in the last month, distinguishing between the following response-categories: never, less than a day a week, 1-2 days a week, 3-4 days a week; 5 or more days a week.

Income The CSEW collects information about gross household income in several categories. For current purposes, we computed the equivalised household disposable income for each individual using data on household composition and using the median income value of the corresponding income category. To do this we used ONS income statistics (ONS 2015b), ${ }^{2}$ and focused in particular on the ratio between gross and disposable income by level of income in the UK. Finally we followed the OECD-modified scale to compute the equivalised household $\operatorname{size}^{3}$ and consequently the equivalised household disposable income for each observation.

Equivalised income was used both in absolute terms and in logarithmic form in our analyses. The two functional forms imply a different relationship between life satisfaction and income, with the logarithmic transformation suggesting that it is the relative change in income rather than the absolute change that affects wellbeing, which some authors claim is a better representation of the income-wellbeing relationship (Kahneman and Deaton 2010).

Additional controls Additional controls were gender, age measured in three categories (16-24 years; 25-44 years; 45-59 years); marital status (single; married or cohabiting; separated/divorced and widower); education (A-level; degree; any other educational level); employment status (employed; unemployed; student; any other inactive); health status, measured on a 5-point scale ranging from very good to very bad; and number of cohabiting children.

Summary statistics of the variables are presented in Table 1.

Table 1 shows that the observed equivalised disposable income was on average $£ 17,817 .{ }^{4}$ Life satisfaction was 7.36 on average, consistent with ONS (2014b) official statistics of approximately 7.5 for England and Wales. As for drug use, approximately onethird of the sample reported having used cannabis at least once in their life, with almost 6\% being current users (consistent with ONS 2014a data) and 27\% being past users. Consumption of other drugs was much lower: $78 \%$ of the sample reported never having tried any other drug in their life, with approximately $4 \%$ being current users (again consistent with ONS $2014 \mathrm{a}$ data) and $18 \%$ being past users. In terms of alcohol consumption, non-drinkers made up $14 \%$ of the sample and around one-third reported drinking less than one day a

\footnotetext{
2 The statistics for 2014/15 have been used for their higher level of detail respect to statistics for 2013/14.

3 The OECD-modified equivalence scale assigns a value of 1 to the head of the family, 0.5 to all other adults and 0.3 to children aged less than 14 . In this analysis, due to the lack of relevant information in the data, we used the age of 16 to distinguish between adults and children.

4 The official statistic provided by ONS (2015b) on household disposable income for the financial year ending in 2014 is $£ 29,477$. However, ONS uses a different equivalence scale assigning 0.67 to the first adult, 0.33 to the second and subsequent adults, and 0.20 for children aged 13 years and under. Using this equivalence scale, the comparable equivalised income of our sample is $£ 26,187$-approximately $10 \%$ less than the official figure. The difference between the official figure on household disposable income and the one observed on our sample is instead approximately $8 \%$ (respectively $£ 31,786$ and $£ 29,265$ ), suggesting that part of the difference in terms of equivalised income derives from a slightly larger (equivalent) household size of our particular sample. One of the reasons behind this is that the sample age is restricted to be less than 59-due to the survey design. Therefore, this excludes all households made up of single elderlies and increases the average household size.
} 
Table 1 Descriptive statistics. Source: Elaborations on CSEW 2013/14

\begin{tabular}{llc}
\hline & M & SD \\
\hline Life satisfaction [0-10] & 7.35 & 2.00 \\
Equivalised disposable income & 17,817 & 12,183 \\
Number of children & 0.66 & 0.99 \\
\hline
\end{tabular}

Cannabis use

Never

Past user

Current user

Other drugs

Never

Past user

Current user

3.75

Alcohol consumption

Never

Less than a day a week

1-2 days a week

30.94

3-4 days a week

14.48

$5+$ days a week

7.72

Gender

Male

Female

Marital status

Single

Married/cohabiting

Separated/divorced

Widowed

Age group

16-24

25-44

45-59

40.05

Health status

Very good

Good

Fair

$\mathrm{Bad}$

Very bad

0.64

Education

Degree

A-level

None/other qualification

Employment condition

Employed

Unemployed 
Table 1 (continued)

\begin{tabular}{lr}
\hline & $\%$ \\
\hline Other inactive & 13.94 \\
$\mathrm{~N}$ & 4405 \\
\hline
\end{tabular}

week. A further third reported drinking 1 or 2 days per week (the group with the highest wellbeing according to Lanier, Nicholson, and Duncan 2001), 14\% reported drinking 3-4 days per week and approximately $8 \%$ reported drinking more frequently.

\section{Empirical Strategy}

\subsection{The Empirical Model}

In terms of our empirical model, we ran a regression analysis of life satisfaction over drug use, alcohol consumption, income and the above-listed set of socio-demographic variables. In particular, we estimated the following model:

$$
L S_{i}=\alpha+D_{i}^{\prime} \boldsymbol{\beta}+\boldsymbol{K}_{i}^{\prime} \gamma+\delta M_{i}+\boldsymbol{X}_{i}^{\prime} \boldsymbol{\theta}+\epsilon_{i}
$$

where $L S_{i}$ is the life satisfaction level of individual i, $\boldsymbol{D}_{\boldsymbol{i}}$ is a vector of drug related variables, $\boldsymbol{K}_{\boldsymbol{i}}$ is a vector of drinking related variables, $M_{i}$ is equivalised disposable income, which enters in the equation in either absolute form (specification (1)) or logarithmic form (specification (2)). $\boldsymbol{X}_{\boldsymbol{i}}$ is a vector of controls, including gender, age, marital status, employment condition, health, education and number of children, and $\epsilon_{i}$ is an error component. The vectors $\boldsymbol{\beta}, \boldsymbol{\gamma}$, and $\delta$ inform us respectively of the association between wellbeing and drug use, drinking and income, while the vector $\boldsymbol{\theta}$ describes its association with the sociodemographic control variables.

Taking current drug users as a reference category, we estimated the coefficients related to never and past users (respectively $\beta_{\text {never drug }}$, and $\beta_{\text {past drug }}$ ), distinguishing between cannabis and other drugs.

\subsection{The Welfare Cost of Taking Drugs}

In the life satisfaction approach, the welfare cost of being a current drug user can be defined as the amount of money individuals would need to receive to compensate them for the detrimental effect taking the drug has on their wellbeing, relative to never and past users. This has been referred to as the "shadow price" (Powdthavee and van den Berg 2011) or "compensation value" (Fujiwara 2013; Fujiwara et al. 2014). The compensation value of being a current versus never drug user is computed as follows:

$$
\text { Compensation Value specification }(1)=\frac{\beta_{\text {never drug }}}{\delta}
$$

Compensation Value specification $(2)=e^{\left[\frac{\beta_{\text {never drug }}}{\delta}+\ln \left(M_{0}\right)\right]}-M_{0}$ 
where $M_{0}$ represents the initial income level-in this case we use the average equivalised income of the sample, while $\delta$ is the coefficient measuring the impact of income on wellbeing. $\beta_{\text {never drug }}$ represents the extra satisfaction a person who has never used drugs enjoys compared to a current user. In a similar way, we can compute the compensation value of being a current user to that of a past user.

For both specifications, the cost of taking the drug is linked to the income coefficient in an inverse relationship. In the semi-log specification, the cost increases with increasing initial income level. ${ }^{5}$

\subsection{The Endogeneity Problem}

As noted above there may be a reciprocal relationship between income and life satisfaction (De Neve and Oswald 2012), with not just income making people more satisfied, but also happier people being more confident and motivated on their job, this leading to an higher income level. Moreover, several unobserved factors are likely to affect both variables, resulting in additional sources of endogeneity (Powdthavee 2010). The estimated coefficient $\delta$, measuring the impact of income on wellbeing, is therefore likely to be biased. To overcome this endogeneity problem, a number of instrumental variables have been used in the empirical literature. Fujiwara et al. (2014) and Apouey and Clark (2015) have, for example, used lottery wins as an instrumental variable for income, following the work previously done by Gardner and Oswald (2007). Alternative instrumental variables used were industry sector (Pischke 2011) and the information about the proportion of household members using a payslip to answer the question about income (Powdthavee 2010). The use of instrumental variables usually leads to an higher income coefficient compared to OLS. Higher income is in fact usually associated with higher overtime working hours which increase stress and negatively affect work-life balance (Golden and Wies-Tuers 2006), as well as with increasing comparison incomes (Ferrer-i-Carbonell 2005).

No suitable instrumental variable was available in the CSEW. Therefore we followed Fujiwara et al. (2014) in retrieving the unbiased estimated coefficient for income $\delta$ from another model to compute the "unbiased" cost of using drugs. This should not be a problem insofar as this is estimated on a representative sample of the same population (this and other issues are further discussed in the Appendix).

We retrieved the "causal effect" of income from the papers by Fujiwara et al. (2014)_ using lottery wins as an instrument—and Powdthavee (2010)—using the information about the use of a payslip during the interview. Using the unbiased income coefficient $\delta^{*}$-drawn

\footnotetext{
5 In the linear specification, the Compensating Value for being a current vs. never drug user is derived by equating the following equations:

$$
\begin{aligned}
L S_{\text {CURRENT DRUG }} & =\delta\left(M_{0}+C V\right) \\
L S_{\text {NEVER DRUG }} & =\beta_{\text {never drug }}+\delta M_{0}
\end{aligned}
$$

As for the semi-log specification, the equations are:

$$
L S_{\text {CURRENT DRUG }}=\delta \ln \left(M_{0}+C V\right)
$$$$
L S_{\text {NEVER DRUG }}=\beta_{\text {never drug }}+\delta \ln \left(M_{0}\right)
$$

In the latter case, the $\mathrm{CV}$ is likely to be higher, as the logarithmic form tends to reduce the effect of any additional income.
} 
from either Fujiwara, Kudrna, and Dolan (2014) or from Powdthavee (2010)—-to compute the "unbiased" compensation value, Eq. (3) can be rewritten in the following way:

$$
\text { "unbiased" Compensation Value specification (2) }=e^{\left[\frac{\beta_{\text {never drug }}}{\delta^{*}}+\ln \left(M_{0}\right)\right]}-M_{0}
$$

\section{Results}

Table 2 reports the results of the estimated model, with income modelled using the linear specification presented in column 1, and modelled using the logarithmic form presented in column 2 . The two specifications produced very similar results.

Individuals who had never used drugs, and even past users, had significantly higher life satisfaction than current drug users. Compared to current cannabis users, life satisfaction was, on average, 0.33 scale points (3.0\%) greater for past users, and 0.54 scale points (or $4.9 \%$ ) greater for never users. Both specifications produced similar relative results. In terms of other drugs, compared to current users, life satisfaction was, on average across the two specifications, 0.35 scale points $(3.2 \%)$ greater for past users, and 0.38 scale points (or $3.5 \%$ ) greater for never users.

The estimated coefficients related to alcohol consumption suggested that, compared to "never" as a reference category, drinking a couple of days a week was positively associated with life satisfaction (a 0.27 scale point or $25 \%$ increase). Drinking more than 5 days a week was negatively but not significantly associated with wellbeing. ${ }^{6}$

The findings for control variables showed that being unemployed, single/divorced and in poor health, was associated with lower life satisfaction than being employed, married and in good health respectively. Moreover, males had significantly lower life satisfaction than females.

Importantly for the current analyses, although the literature suggests that the relationship between wellbeing and income may be better described by a semi-log model, our results, in terms of goodness of fit measures such as the log likelihood and Akaike's Information Criteria, suggested that the linear specification performs better, at least in the current context.

\footnotetext{
${ }^{6}$ Alternative specifications have been estimated. All results are available from the authors upon request. First, we included an interaction term between other drugs and cannabis. This variable can take 4 different values depending on whether the respondent has never taken any of these drugs, has taken both types of drug in the past, has taken one drug in the past and is taking one in the present, or is a current user of both drugs. Introducing the interaction terms, all coefficients related to the drug variables turned out not significant (both for cannabis and other drugs and for the interaction terms). This may be linked to the relatively low number of individuals taking drugs other than cannabis in our sample.

Second, we included an interaction term between alcohol consumption and drug use. Given that alcohol use is measured only in the present, we have introduced an interaction term of current drug use (of either cannabis or any other drug) and frequency of alcohol consumption. The coefficients and significance level of the original alcohol variables did not change, but the interaction terms between alcohol and drug use were not significant. Again, it should be noted that the data does not allow us to know whether alcohol and drugs have been taken together on the same occasions.

Third we also attempted to separate out other types of drugs, but found little significant impact on wellbeing - probably due to the low numbers of consumers and the lack of data about frequency. In addition we tried to categorise by type of drug (opiate, stimulant, downers, cocaine, amphetamine or Class A) but no significant impacts were found.
} 
Table 2 Estimation results. Source: Elaborations on CSEW 2013/14

(1)

Linear model

(2)

Semi-log model

Cannabis use

Current user (ref.cat)

Never user

$0.541 * * *$

$0.530 * * *$

(0.160)

(0.160)

Past user

$0.329 * *$

$0.331 * *$

(0.154)

(0.155)

Other drugs

Current user (ref.cat)

Never user

$0.368 * *$

$0.388^{* *}$

(0.182)

(0.182)

Past user

$0.343 *$

$0.353^{*}$

(0.180)

(0.180)

Alcohol consumption

Never (ref. cat.)

Less than a day a week

0.126

0.118

(0.103)

(0.103)

1-2 days a week

$0.270 * * *$

$0.267 * *$

(0.103)

(0.104)

3-4 days a week

0.125

0.131

(0.116)

(0.116)

$5+$ days a week

$-0.115$

$-0.106$

(0.136)

(0.137)

Male

$-0.225^{* * * *}$

$-0.220 * * *$

(0.058)

(0.058)

Age group

16-24 (ref. cat.)

25-44

$-0.186^{*}$

$-0.184^{*}$

(0.109)

(0.110)

$-0.159$

$-0.161$

(0.116)

(0.117)

Marital status

Single (ref. cat.)

Married/cohabiting

$0.300 * * *$

$0.290^{* * * *}$

(0.071)

(0.071)

Separated/divorced

$-0.228 * *$

$-0.228 * *$

(0.101)

(0.101)

Widowed

$-0.505^{*}$

$-0.497 *$

$(0.275)$

(0.276)

-0.601 ***

$-0.607 * * *$

(0.041)

(0.041)

Educational level

None/Other qualification (ref. cat.)

Degree 
Table 2 (continued)

(1)

Linear model
$(2)$

Semi-log model

A-level
Employment condition
Employed (ref. cat.)
Unemployed

(0.082)

$-0.788 * * *$

$-0.754 * * *$

(0.168)

(0.170)

Student

0.273

(0.186)

$0.317^{*}$

$-0.214^{* *}$

(0.188)

Other inactive

$-0.193 * *$

$0.076 * *$

(0.033)

Equivalised disposable income

$0.017 * * *$

(0.003)

Log of Equivalised disposable income

$0.217^{* * * *}$

(0.044)

$7.435 * * *$

$7.161 * * *$

(0.233)

(0.247)

4405

4405

N

R squared

$-8966.667$

$-8971.240$

0.138

0.136

$17,979.333$
$17,988.48$

The income variable has been divided by 1000 for the ease of interpretation; health status is an ordinal variable

$* * * p<0.01 ; * * p<0.05, * p<0.10$

\section{Discussion}

The regression results confirmed the harmful effect of using drugs on wellbeing. We found a difference in terms of types of drugs, with cannabis having a more detrimental effect than other types of drugs. This may be the result of the hypothesized lower frequency of use of drugs different from cannabis-which cannot be further investigated due to lack of data, or it may be indicative of a persistence in the wellbeing impacts of cannabinoids.

The result on alcohol consumption suggested that social drinkers have a higher life satisfaction than abstainers. This confirms previous literature findings interpreting "recreational" drinking as a strategy to deal with stress or promote positive social relationships (Lanier, Nicholson, and Duncan 2001). Nevertheless, it is not possible to know whether it is drinking itself that increases wellbeing, or it is rather the time spent outside with friends that gives higher life satisfaction to those who drink in moderation.

Looking at the regression coefficients presented in Table 2, for a better understanding of the effect of drugs and drinking on our wellbeing, we can compare the magnitude of their effect to the effect of different variables. The positive effect of never having taken cannabis was similar but with opposite sign to the effect of being widowed. Hence, a widow/er 
Table 3 The compensation value of taking drugs and drinking by model specification
(1)

Linear model

(2)

Semi-log model

Cannabis: current user versu

\begin{tabular}{lll} 
Never user & $£ 32,788$ & $£ 187,089$ \\
Past user & $£ 19,939$ & $£ 64,083$ \\
Other drugs: current user versus & & \\
Never user & $£ 22,303$ & $£ 88,686$ \\
Past user & $£ 20,788$ & $£ 72,822$ \\
Drinking: never versus & & \\
1-2 days a week & $£ 16,364$ & $£ 43,164$ \\
\hline
\end{tabular}

that has never used cannabis is on average as happy as a single individual (controlling for age) who currently uses cannabis. A similar comparison can be made between being single versus married and using other kinds of drugs or not. Being in education vs. employed had a very close coefficient to drinking a couple of days a week vs. abstinence, although the former was hardly significant.

\subsection{Policy Implications}

In order to derive the policy implications of our findings, Table 3 presents the estimated wellbeing cost of being a current vs. past drug user and of being a current vs. never user. These figures have been computed following the procedure presented in Sect. 4.2, and in particular Eqs. (2) and (3), together with the regression results presented in Table 2. Equations (2) and (3) have been duly modified for computing the compensation value for being a current vs. past user, and the compensation value for not drinking alcohol vs. being a moderate drinker. As shown in Table 3, depending on the model specification (i.e. linear or semi-log specification), never having used cannabis was associated with wellbeing benefits equivalent to an extra $£ 32,788-£ 187,089$ per annum compared to current users. Similarly, the compensation a past user would need to maintain their wellbeing if they were to become a current user was estimated to be in the $£ 19,939-£ 64,083$ per annum range, depending on specification. As for other drugs, never having taken the drug was found to be "worth" $£ 22,303-£ 88,686$ per annum compared to current users and being a past user was associated with $£ 20,788-£ 72,822$ per annum, worth of wellbeing gains compared to current users.

These estimates may be useful in conducting cost-benefit analysis of actions to rehabilitate drug users or in actions to prevent drug use. For the case of rehabilitation, the cost of being a current user compared to being a past user should be used. When considering actions to prevent drug use (e.g. education campaigns) then the cost of being a current user compared to never using the drug in question should be used. It is important to note the persistent impact of drug taking on wellbeing.

These figures suggest that a policy intervention aimed at overcoming drug addiction (giving up current use and becoming a past user) may lead to a yearly $£ 20,000$ gain following the linear specification for both use of cannabis and other drugs, and over $£ 60,000$ for cannabis and over $£ 70,000$ in the case of other drugs, following the semi-log specification.

As for drinking, we found that drinking a couple of days a week rather than never was equivalent to an extra income of $£ 16,364$ in the linear specification and $£ 43,164$ in 
Table 4 The compensation value of taking drugs and drinking by income coefficient estimate (semi-log specifications only)

(1)

CSEW OLS-specifica-

tion (2)
(2)

CSEW using Powdthavee IV (upper bound)
(3)

CSEW using FKD IV (lower bound)

Cannabis: current user versus

\begin{tabular}{lccc} 
Never user & $£ 187,089$ & $£ 65,724$ & $£ 5631$ \\
Past user & $£ 64,083$ & $£ 28,950$ & $£ 3333$ \\
Other drugs: current user versus & & \\
Never user & $£ 88,686$ & $£ 37,404$ & $£ 3967$ \\
Past user & $£ 72,822$ & $£ 32,047$ & $£ 3576$ \\
Drinking: never versus & & & $£ 2643$ \\
$1-2$ days a week & $£ 43,164$ & $£ 20,989$ & \\
\hline
\end{tabular}

the semi-log specification. Intriguingly, according to the ONS (2017) average household expenditures on alcoholic drinks in the UK is $£ 405$ per year. Clearly the cost for alcohol consumption is far less than the potential income equivalent benefit from moderate drinking in terms of life satisfaction.

As discussed earlier, an endogeneity problem for income exists. As no suitable instrumental variable was available in the CSEW, we have retrieved the unbiased estimated coefficient for income $\delta^{*}$ from the papers by Powdthavee (2010) and Fujiwara et al. (2014) (FKD hereafter). ${ }^{7}$ As both Powdthavee and FKD studies model the relationship between life satisfaction and income following a semi-logarithmic form, in the following we are going to focus on specification 2 only.

Table 4 presents the estimated unbiased cost of taking drugs, or the unbiased value of being a moderate drinker, computed following Eq. (4) and using Powdthavee (2010) and FKD unbiased income coefficient.

In particular, Table 4 presents three sets of results. Column 1 reports for a comparison the compensation values already presented in Table 3 following Specification 2. Column 2 presents the compensation values of taking drugs and drinking computed using the results of the unbiased income coefficient derived from the Powdthavee's paper; Column 3 presents the ones computed following the FKD paper. As it is also discussed in the Appendix, the figures in column 2 may be considered an upper bound of the "unbiased" cost of drugs and drinking, while the figures in column 3 may be considered a "lower bound". These figures clearly suggest that when the endogeneity issue is taken into account, the wellbeing cost of taking drugs is sharply reduced. Following the Powdthavee (2010) income estimate, the cost of taking drugs ended up being between 55 and $65 \%$ lower than our estimate, while following the FKD paper, this was reduced to less than $10 \%$ of our original estimates. Of note, the values computed following FKD estimates were not far from the benefit of being off drugs estimated by DTORS (Donmall et al. 2009): approximately $£ 6500$ per person a year.

Turning to drinking behaviours, according to our estimates in the semi-log specification drinking a couple of days a week rather than never was equivalent to an extra income

\footnotetext{
7 These are presented and discussed in the "Appendix".
} 
Table 5 The benefits of giving up drugs at the national level

\begin{tabular}{lll}
\hline Estimated number & $\begin{array}{l}\text { Wellbeing } \\
\text { benefit from } \\
\text { giving up }\end{array}$ \\
\hline Current cannabis users & $1.862 \mathrm{~m}$ & $£ 6.208 \mathrm{bn}$ \\
Current users of other drugs & $1.256 \mathrm{~m}$ & $£ 4.491 \mathrm{bn}$ \\
Total wellbeing benefits & & $£ 10.700 \mathrm{bn}$ \\
\hline
\end{tabular}

of $£ 43,164$ a year. Taking into account the income endogeneity problem and following the same procedure used for evaluating drugs, we found that the unbiased value of being a social drinker was $£ 20,989$ following Powdthavee’s (2010) estimates and $£ 2643$ following the FKD study (Table 4). These figures are still significantly higher than the overall average cost of alcohol consumption of $£ 405$ per household per year (ONS 2017).

\subsection{The Potential Wellbeing Benefits of Giving Up Drugs at the National Level}

Considering the drug consumption statistics presented in Table 1, it is possible to calculate the total wellbeing benefits of giving up drugs at the national level. In England and Wales the population aged 16 to 59 years (the age group of our data sample) is made up of approximately $33.5 \mathrm{~m}$ people (ONS 2016b), as the CSEW is a representative sample, we estimated the number of users on the basis of this population. In order to give figures which are as conservative as possible, changes in drug use habits were evaluated following the results derived using the FKD estimates (last column of Table 4).

Table 5 presents the wellbeing benefits current drug users may enjoy from giving up drugs. The potential benefit of giving up drugs was $£ 10.7 \mathrm{bn}$ per year for England and Wales. This represents $0.6 \%$ of UK GDP in 2013. This benefit only reflects the wellbeing element, it does not reflect the potential reductions in healthcare costs or other associated costs of drug use (e.g. crime) - it is hence a lower bound. A number of studies have calculated the direct and indirect health and crime cost linked to illegal drug use for society. This is approximately $0.19 \%$ of GDP for Belgium (Lievens et al. 2017), 0.14\% of GDP for Spain (Rivera et al. 2017) and $0.4 \%$ in the case of France (Kopp and Ogrodnik 2017).

In order to get a better grasp of the importance of the issue of drug use to society in comparison to other social issues, we can compare the benefit of giving up drugs to the avoidance of other social problems. For instance, our findings are in the same ballpark as the social cost of smoking, which is $£ 13.74$ billion in the UK (Nash and Featherstone 2010 ), but lower than the social cost of air pollution, which is $£ 54$ billion per year in the UK (WHO and OECD 2015). There are significant threats to public health budgets around drug prevention and support services and it is important that efforts be made to reduce the significant costs to individuals and to society.

\section{Summary}

This paper explores the relationship between drug use and wellbeing, distinguishing between cannabis and other types of drugs, and between current and past drug users. Our results suggest a significant harmful effect of taking drugs on wellbeing, with individuals 
never having used cannabis having, for example, a life satisfaction score which is over 0.5 higher compared to individuals that are currently using drugs.

Taking into account endogeneity in the relationship between income and wellbeing, we found that the compensating value for being a current cannabis user compared to not using the drug was between $£ 5631$ to $£ 65,724$. The similar cost for other drug use amounted to between $£ 3967$ to $£ 37,404$.

We also computed the effect of drinking on wellbeing, finding that drinking a couple of times a week rather than never is associated with extra 0.27 points life satisfaction. The welfare gain associated to being a social drinker is between $£ 2643$ and $£ 20,989$ a year.

As is true of any study of this type, our analysis suffers from a number of limitations. The data did not include information on intensity and frequency of drug use, so it was not possible to distinguish between occasional drug use and regular use. Moreover, we did not know how long before the interview the drug had been taken (e.g. could have been almost 12 months ago), whether different types of drugs were taken together, or whether alcohol and drugs were mixed. Also, our focus was on the association between current use and wellbeing and we were unable to consider the effects of past users experiencing withdrawal symptoms which can also negatively affect wellbeing (Looby and Earleywine 2007).

Another issue which has already been highlighted in the existing literature is that the use of drugs (as well as of alcohol) is likely to be linked to wellbeing in a bidirectional relationship. Given the cross-sectional nature of the dataset used, we were not able to fully address this issue. Therefore, we must be aware that the estimated coefficients reflect associations rather than causal relationships. To mitigate this problem, we have controlled for a number of personal characteristics, such as health status, employment condition and marital status, which could at least in part explain the endogeneity issue. Further research is needed into these relationships, including both qualitative work and improved data collection to facilitate the quantitative analysis of these relationships using, for example, structural equation models.

We were also unable to explore in greater depth the impact of other types of drugs because of a lack of data. It is likely that different drugs will have varying impacts on wellbeing.

We also computed the overall potential wellbeing benefit that could be enjoyed by giving up drugs at the national level. This was estimated to be $£ 10.7$ billion per year in England and Wales. This is equivalent to the social cost of smoking-and suggests there is much to be gained from strategies to reduce drug use. Moreover, this figure does not accounts for the wider benefits of reducing drug use to society-in terms of crime and the wider health implications. However, the wellbeing benefits of reducing drug use are shown to be high, even under the most conservative assumptions. Drug prevention and support services need to be appropriately funded to ensure that some of these benefits can be captured.

\section{Conclusions}

This paper has presented a first attempt to value the impact of alcohol and drug use using the wellbeing valuation approach. The findings suggest that, in terms of wellbeing, there is a small benefit to moderate alcohol consumption. In terms of drugs, current and past drug use is associated with important reductions in wellbeing-which would suggest that efforts 
need to be placed into services to discourage illicit drug use and that future drug policy (including legalisation) should be carefully designed with societal wellbeing in mind.

The values for current losses may seem unrealistically high, compared to the average level of income of the population. Moreover, if we asked people how much they would be willing to pay to avoid the negative consequences of drug misuse, the numbers we would likely get would be much lower. This is because eliciting information on willingness to pay for non-market goods using survey methods is constrained by the budgets of the individuals. On the other hand, the life satisfaction approach does not depend on income ${ }^{8}$ and using such estimates in cost-benefit analysis may lead to better estimation of the true gains in welfare terms from the promotion of drug avoidance.

Acknowledgements This study was carried out within the project "Valuing the health benefits of city wellbeing" (Project no. 132025) funded by Innovate UK. This document presents results drawn from the Crime Survey for England and Wales (CSEW). The ONS CSEW data are Crown copyright materials, used with the permission of the Controller of HMSO. The CSEW is sponsored by Home Office, Ministry of Justice and ONS and data were collected by TNS BMRB. The microdata were made available by the UK Data Archive of University of Essex. The interpretation of this data and other views expressed in this text are those of the authors, which bear full responsibility for all errors and omissions in the analysis and interpretation of the CSEW data. No responsibility is borne by UK Data Archive, UK Data Service, the data creator, the copyright holder and the funders.

\section{Compliance with Ethical Standards}

Conflict of interest The authors declare they have no conflict of interest.

Open Access This article is distributed under the terms of the Creative Commons Attribution 4.0 International License (http://creativecommons.org/licenses/by/4.0/), which permits unrestricted use, distribution, and reproduction in any medium, provided you give appropriate credit to the original author(s) and the source, provide a link to the Creative Commons license, and indicate if changes were made.

\section{Appendix}

In this study we retrieved the "causal effect" of income on life satisfaction from two papers using for this end an instrumental variable approach. In particular, Fujiwara et al. (2014) used lottery wins as an instrument, while Powdthavee (2010) used the information about the use of a payslip during the interview. In using the estimated coefficients from these papers, a number of caveats should be taken into account. First, both analyses used British Panel Household Survey (BHPS) data, which are actually representative of the UK as a whole, while the CSEW is representative of England and Wales only. Given that the population of England and Wales makes up almost $90 \%$ of the overall British population (ONS 2016b) we do not believe this will unduly influence our results. Second, BHPS measures life satisfaction on a 1-7 scale, while the CSEW uses a 0-10 scale. Following Easterlin and Onnicha (2009), we assume that the two measurement scales can be linearly rescaled, and that a life satisfaction equal to 0 in the $0-10$ scale corresponds to a life satisfaction of 1 in the 1-7 scale, while scoring the maximum of 10 in the $0-10$ scale is equivalent to scoring

\footnotetext{
8 see Powdthavee and Van den Berg (2011) on this issue and on the differences between contingent valuation methods and the life satisfaction approach in the valuation of health and social outcomes, as well as on the limits of the two methods.
} 
Table 6 Comparison of the estimated regression coefficients of income

\begin{tabular}{llllll}
\hline & \multicolumn{2}{l}{ Original 1-7 scale } & & \multicolumn{2}{l}{$\begin{array}{l}\text { Transformed 0-10 } \\
\text { scale }\end{array}$} \\
\cline { 2 - 3 } \cline { 5 - 6 } \cline { 5 - 6 } & OLS & IV & & OLS & IV \\
\hline Powdthavee (2010) & 0.105 & $0.206^{\mathrm{a}}$ & & 0.175 & 0.343 \\
Fujiwara et al. (2014) & $0.124-0.132^{\mathrm{b}}$ & 1.158 & & $0.207-0.220$ & 1.930 \\
CSEW (our estimate) & & & & 0.217 & \\
\hline
\end{tabular}

${ }^{\mathrm{a}}$ This is the result of the IV-FE model

${ }^{\mathrm{b}}$ The OLS model is computed on Understanding Society data

7 in the BHPS scale. This can equivalently be done by transforming the estimated income coefficient computed on BHPS data multiplying it by 10/6. Third, while both papers also used a semi-log functional form for income (as we do in specification 2), in the current paper income is defined in a slightly different way. Fujiwara et al. (2014) used equivalised household income but did not specify the equivalence scale used. Powdthavee (2010) used the square root of the number of household members to derive the equivalent household income. Nevertheless, he also stated that when changing the definition of income, its coefficient remained "virtually the same" (p. 85). These issues notwithstanding, we believe that using the estimated coefficients from these papers is thus not unreasonable, and consider them as estimates of the causal effect of income on wellbeing.

Table 6 presents the income coefficient estimates from the studies by Powdthavee (2010) and Fujiwara et al. (2014). Both OLS and IV estimates are reported. Comparing OLS and IV regression coefficients, one can see that in both cases the IV estimate is higher than the OLS. This is in line with the literature, which suggests that higher income usually comes with longer working hours, as well as with higher comparison incomes, both of which increase stress reducing wellbeing.

As both studies by by Powdthavee (2010) and Fujiwara et al. (2014) used life satisfaction data measured on a 1-7 scale, Table 6 also presents the coefficient linearly transformed onto a 0-10 scale (as explained above), and, for a comparison, our estimated coefficient based on the CSEW data.

Although the OLS estimates reported in Table 6 are quite close to each other (and to our coefficient as well), the two IV estimates differ substantially. This is likely to be the result of the different control variables used in these regressions, with Powdthavee (2010) considering a much larger control vector than FKD (2014). ${ }^{9}$ We used the values of 0.343 and 1.930 as possible bounds of the unbiased income coefficient $\delta^{*}$, and computed what we consider the "lower" and "upper bound" of the unbiased cost of taking drugs, or the unbiased value of being a moderate drinker, following Eq. (4). These are presented in Table 4 in the text.

\footnotetext{
${ }^{9}$ On the effect of additional controls see e.g. the models presented in tables IV to VI by Angrist and Krueger (1991).
} 


\section{References}

Allen, J., \& Holder, M. D. (2014). Marijuana use and well-being in university students. Journal of Happiness Studies, 15, 301-321. https://doi.org/10.1007/s10902-013-9423-1.

Anderson, D. M., Rees, D. I., \& Sabia, J. J. (2014). Medical marijuana laws and suicides by gender and age. American Journal of Public Health, 104(12), 2369-2376. https://doi.org/10.2105/AJPH.2013.301612.

Angrist, J. D., \& Krueger, A. B. (1991). Does compulsory school attendance affect schooling and earnings? The Quarterly Journal of Economics, 106(4), 979-1014. https://doi.org/10.2307/2937954.

Apouey, B., \& Clark, A. E. (2015). Winning big but feeling no better? The effect of lottery prizes on physical and mental health. Health Economics, 24, 516-538. https://doi.org/10.1002/hec.3035.

Arnett, J. J. (2005). The developmental context of substance use in emerging adults. Journal of Drug Issues, 35(2), 235-254. https://doi.org/10.1177/002204260503500202.

Baumberg Geiger, B., \& MacKerron, G. (2016). Can alcohol make you happy? A subjective wellbeing approach. Social Science and Medicine, 156, 184-191. https://doi.org/10.1016/j.socsc imed.2016.03.034.

Bennet, T. H., \& Holloway, K. R. (2005). Disaggregating the relationship between drug misuse and crime. The Australian and New Zealand Journal of Criminology, 38(1), 102-121. https://doi. org/10.1375/acri.38.1.102.

Bennet, T. H., \& Holloway, K. R. (2015). Drug use among college and university students: Findings from a national survey. Journal of Substance Use, 20(1), 50-55. https://doi.org/10.3109/14659 891.2013.878762.

Bennet, T. H., Holloway, K. R., \& Farrington, D. (2008). The statistical association between drug misuse and crime: A meta-analysis. Aggression and Violent Behavior, 13, 107-118. https://doi. org/10.1016/j.avb.2008.02.001.

Brook, D., Brook, J., Zhang, C., Cohen, P., \& Whiteman, M. (2002). Drug use and the risk of major depressive disorder, alcohol dependence and substance abuse disorders. Archives of General Psychiatry, 59, 1039-1044. https://doi.org/10.1001/archpsyc.59.11.1039.

Corman, H., Noonan, K., Reichman, N. R., \& Schwartz-Soicher, O. (2011). Life shocks and crime: A test of the "turning point" hypothesis. Demography, 48, 1177-1202. https://doi.org/10.1007/s1352 4-011-0042-3.

Cross, J., Johnson, B. D., Davis, W. R., \& Liberty, H. J. (2001). Supporting the habit: income generation activities of frequent crack users compared with frequent users of other hard drugs. Drug and Alcohol Dependence, 64, 191-201. https://doi.org/10.1016/S0376-8716(01)00121-1.

Davies, L., Jones, A., Vamvakas, G., Dubourg, R., \& Donmall, M. (2009). The drug treatment outcomes research study (DTROS): Cost-effectiveness analysis. Research Report, 25. London: Home Office.

De Neve, J. E., \& Oswald, A. J. (2012). Estimating the influence of life satisfaction and positive affect on later income using sibling fixed effects. PNAS: Proceedings of the national academy of sciences, 109(49), 19953-19958. https://doi.org/10.1073/pnas.1211437109.

Dietze, P., Jenkinson, R., Aitken, C., Stoové, M., Jolley, D., Hickman, M., et al. (2013). The relationship between alcohol use and injecting drug use: Impacts on health, crime and wellbeing. Drug and Alcohol Dependence, 128, 111-115. https://doi.org/10.1016/j.drugalcdep.2012.08.013.

Donmall, M., Jones, A., Davies, L., \& Barnard, M. (2009). Summary of key findings from the drug treatment outcomes research study (DTORS). Research Report, 23. London: Home Office.

Easterlin, R. A., \& Onnicha, S. (2009). Happiness and we assume economic growth: Does the cross section predict time trends? Evidence from developing countries. IZA discussion papers, No. 4000

Ferrer-i-Carbonell, A. (2005). Income and well-being: An empirical analysis of the comparison income effect. Journal of Public Economics, 89, 997-1019. https://doi.org/10.1016/j.jpubeco.2004.06.003.

Fujiwara, D. (2013). The social impact of housing providers. HACT. www.hact.org.uk. Accessed October 2016.

Fujiwara, D., Kudrna, L., \& Dolan, P. (2014). Quantifying and valuing the wellbeing impacts of culture and sport. Report for Department of Culture, Media and Sport. https://www.gov.uk/government /uploads/system/uploads/attachment_data/file/304899/Quantifying_and_valuing_the_wellbeing_ impacts_of_sport_and_culture.pdf. Accessed October 2016.

Gardner, J., \& Oswald, A. J. (2007). Money and mental wellbeing: A longitudinal study of mediumsized lottery wins. Journal of Health Economics, 26, 49-60. https://doi.org/10.1016/j.jheal eco.2006.08.004.

Gil-Lacruz, A. I., \& Gil-Lacruz, M. (2010). Does alcohol consumption reinforce mental problems in adolescence? The Journal of Socio-Economics, 39, 223-232. https://doi.org/10.1016/j.socec.2009.12.010.

Golden, L., \& Wies-Tuers, B. (2006). To your happiness? Extra hours of labor supply and worker wellbeing. The Journal of Socio-Economics, 35, 382-397. https://doi.org/10.1016/j.socec.2005.11.039. 
HM Treasury (2011). The green book: Appraisal and evaluation in central government. Treasury guidance. HM Treasury, London. Available online at https://www.gov.uk/government/uploads/system/ uploads/attachment_data/file/220541/green_book_complete.pdf. Accessed December 2015.

Kahneman, D., \& Deaton, A. (2010). High income improves evaluation of life but not emotional wellbeing. PNAS: Proceedings of the National Academy of Sciences, 107(38), 16489-16493. https:// doi.org/10.1073/pnas.1011492107.

Kopak, A. M., Vartanian, L., Hoffman, N. G., \& Hunt, D. E. (2014). The connections between substance dependence, offense type, and offense severity. Journal of Drug Issues, 44(3), 291-307. https://doi. org/10.1177/0022042613511439.

Kopp, P., \& Ogrodnik, M. (2017). The social cost of drugs in France in 2010. European Journal of Health Economics, 18, 883-892. https://doi.org/10.1007/s10198-016-0835-9.

Lanier, C. A., Nicholson, T., \& Duncan, D. (2001). Drug use and mental wellbeing among a sample of undergraduate and graduate college students. Journal of Drug Education, 31(3), 239-248. https://doi. org/10.2190/r7t3-t266-jn9e-ux3w.

Levitt, S. D. (1998). Juvenile crime and punishment. The Journal of Political Economy, 106(6), 1156-1185. https://doi.org/10.1086/250043.

Levy, A. (2008). A theory of entrenched socioeconomic deprivation and addiction to strong mind-altering substances. The Journal of Socio-Economics, 37, 1756-1767. https://doi.org/10.1016/j.socec .2007.12.007.

Lievens, D., Vander Laenen, F., Verhaeghe, N., Putman, K., Pauwels, L., Hardyns, W., et al. (2017). Economic consequences of legal and illegal drugs: The case of social costs in Belgium. International Journal of Drug Policy, 44, 50-57. https://doi.org/10.1016/j.drugpo.2017.03.005.

Looby, A., \& Earleywine, M. (2007). The impact of methamphetamine use on subjective well-being in an Internet survey: Preliminary findings. Human Psychopharmacology: Clinical and Experimental, 22, 167-172. https://doi.org/10.1002/hup.831.

MacDonald, Z., \& Pudney, S. (2000). Illicit drug use, unemployment, and occupational attainment. Journal of Health Economics, 19, 1089-1115. https://doi.org/10.1016/S0167-6296(00)00056-4.

Miller, P., \& Plant, M. (2002). Heavy cannabis use among UK teenagers: An exploration. Drug and Alcohol Dependence, 65, 235-242. https://doi.org/10.1016/S0376-8716(01)00165-X.

Moore, T. H. M., Zammit, S., Lingford-Hughes, A., Barnes, T. R. E., Jones, P. B., Burke, M., et al. (2007). Cannabis use and risk of psychotic or affective mental health outcomes: A systematic review. Lancet, 370, 319-328. https://doi.org/10.1016/S0140-6736(07)61162-3.

Nash, R., \& Featherstone, H. (2010). Cough up: Balancing tobacco income and costs in society. Policy Exchange Research Note, March 2010. Available online at https://www.policyexchange.org.uk/wpcontent/uploads/2016/09/cough-up-march-10.pdf

ONS. (2014a). Drug misuse: Findings from the 2013/14 crime survey for England and Wales. London: Home Office.

ONS (2014b). Personal well-being estimates geographical breakdown, April 2013 to March 2014. Dataset available at http://www.ons.gov.uk/peoplepopulationandcommunity/wellbeing/datasets/personalwe llbeingestimatesgeographicalbreakdown. Accessed August 2017

ONS. (2015a). User guide to crime statistics for England and Wales-October 2015. London: Home Office.

ONS (2015b). The effects of taxes and benefits on household income. ONS Dataset available at: http://www. ons.gov.uk/peoplepopulationandcommunity/personalandhouseholdfinances/incomeandwealth/datasets/ theeffectsoftaxesandbenefitsonhouseholdincomefinancialyearending2014. Accessed November 2016

ONS. (2016a). Drug misuse: Findings from the 2015/16 crime survey for England and Wales. London: Home Office.

ONS (2016b). Population estimates for UK, England and Wales, Scotland and Northern Ireland. ONS Dataset available at: https://www.ons.gov.uk/peoplepopulationandcommunity/populationandmigration/ populationestimates/datasets/populationestimatesforukenglandandwalesscotlandandnorthernireland. Accessed November 2017.

ONS (2017). Family spending in the UK: Financial year ending March 2016. Statistical Bulletin. Available from: https://www.ons.gov.uk/peoplepopulationandcommunity/personalandhouseholdfinances/expen diture/bulletins/familyspendingintheuk/financialyearendingmarch2016. Accessed August 2017.

ONS and TNS (2014). The 2013/14 crime survey for England and Wales (Vol. 1). Technical Report.

Orlowski, J., \& Wicker, P. (2015). The monetary value of social capital. Journal of Behavioral and Experimental Economics, 57, 26-36. https://doi.org/10.1016/j.socec.2015.04.007.

Oswald, A. J., \& Powdthavee, N. (2008). Death, happiness, and the calculation of compensatory damages. The Journal of Legal Studies, 37(S2), S217-S251. https://doi.org/10.1086/595674.

Peretti-Watel, P. (2006). Cognitive dissonance and risk denial: The case of cannabis use in adolescents. The Journal of Socio-Economics, 35, 1032-1049. https://doi.org/10.1016/j.socec.2005.11.023. 
Pischke, J. S. (2011). Money and happiness: Evidence from the industry wage structure. National Bureau of Economic Research Working Paper, 17056. https://doi.org/10.3386/w17056.

Powdthavee, N. (2008). Putting a price tag on friends, relatives, and neighbours: Using surveys of life satisfaction to value social relationships. The Journal of Socio-Economics, 37, 1459-1480. https://doi. org/10.1016/j.socec.2007.04.004.

Powdthavee, N. (2010). How much does money really matter? Estimating the causal effects of income on happiness. Empirical Economics, 39, 77-92. https://doi.org/10.1007/s00181-009-0295-5.

Powdthavee, N., \& van den Berg, B. (2011). Putting different price tags on the same health condition: Reevaluating the well-being valuation approach. Journal of Health Economics, 30, 1032-1043. https:// doi.org/10.1016/j.jhealeco.2011.06.001.

Qary, S. (2014). Marriage, adaptation and happiness: Are there long-lasting gains to marriage? Journal of Behavioral and Experimental Economics, 50, 29-39. https://doi.org/10.1016/j.socec.2014.01.003.

Rivera, B., Casal, B., \& Currais, L. (2017). The social cost of illicit drugs use in Spain. International Journal of Drug Policy, 44, 92-104. https://doi.org/10.1016/j.drugpo.2017.03.012.

Semple, S. J., Patterson, T. L., \& Rant, I. (2005). Methamphetamine use and depressive symptoms among heterosexual men and women. Journal of Substance Use, 10(1), 31-47. https://doi.org/10.1080/14659 89042000271264.

Tartaglia, S., Gattino, S., \& Fedi, A. (2017a). Life satisfaction and alcohol consumption among young adults at social gatherings. Journal of Happiness Studies. https://doi.org/10.1007/s10902-017-9907-5.

Tartaglia, S., Miglietta, A., \& Gattino, S. (2017b). Life satisfaction and cannabis use: A study on young adults. Journal of Happiness Studies, 18, 709-718. https://doi.org/10.1007/s10902-016-9742-0.

Tsurumi, T., \& Managi, S. (2016). Monetary valuations of life conditions in a consistent framework: The life satisfaction approach. Journal of Happiness Studies. https://doi.org/10.1007/s10902-016-9775-4.

Walker, K., Bowen, E., \& Brown, S. (2013). Psychological and criminological factors associated with desistance from violence: A review of the literature. Aggression and Violent Behavior, 18, 286-299. https://doi.org/10.1016/j.avb.2012.11.021.

WHO Regional Office for Europe, \& OECD. (2015). Economic cost of the health impact of air pollution in Europe: Clean air, health and wealth. Copenhagen: WHO Regional Office for Europe.

\section{List of datasets}

Office for National Statistics, May 2015. Crime Survey for England and Wales, 2013-2014 [computer file]. 2nd Edition. Colchester, Essex: UK Data Archive [distributor]. SN: 7619. https://doi.org/10.5255/ UKDA-SN-7619-2.

Office for National Statistics, May 2015. Crime Survey for England and Wales, 2013-2014: Special Licence Access, Low-Level Geographic Data [computer file]. 2nd Edition. Colchester, Essex: UK Data Archive [distributor]. SN: 7620. https://doi.org/10.5255/UKDA-SN-7620-2.

Office for National Statistics, January 2015. Crime Survey for England and Wales, 2013-2014: Special Licence Access, Drinking Behaviour Module [computer file]. Colchester, Essex: UK Data Archive [distributor]. SN: 7622. https://doi.org/10.5255/UKDA-SN-7622-1.

Office for National Statistics, January 2015. Crime Survey for England and Wales, 2013-2014: Special Licence Access, Drug Use Module [computer file]. Colchester, Essex: UK Data Archive [distributor]. SN: 7623. https://doi.org/10.5255/UKDA-SN-7623-1.

Publisher's Note Springer Nature remains neutral with regard to jurisdictional claims in published maps and institutional affiliations. 